\title{
VISÃO EMPREENDEDORA: CASO DE SUCESSO EMPRESARIAL DA AMANDA BEAUTY CENTER
}

\author{
Cleide Ferreira Alves ${ }^{\mathrm{I}}$
}

RESUMO: A pesquisa teve como objetivo, verificar a trajetória empreendedora da Empresa Amanda Beauty Center, tendo como método científico, um estudo de caso para verificar os principais desafios encontrados, até chegar ao sucesso da empresa. Para conhecer mais sobre o surgimento da empresa, se fez necessário verificar e, acompanhar entrevistas do sócio administrador. As entrevistas foram publicadas nas mídias sociais e jornais locais impressos, facilitando entender o nascimento da empresa e o caminho percorrido pela sua fundadora Amanda Procópio. A pesquisa aborda o tema empreendedorismo, mas também, o processo de sucessão da empresa familiar, tendo como os principais desafios, a continuidade do negócio bem-sucedido. Neste sentido, o artigo possibilita a investigação de outros temas, que podem servir para futuras pesquisas.

Palavras chaves: Empreendedorismo. Empreendedor. Empresa familiar.

ABSTRACT: The research had as objective, to verify the entrepreneurial trajectory of the Amanda Beauty Center Company, having as a scientific method, a case study to verify the main challenges encountered, until reaching the company's success. To learn more about the company's emergence, it was necessary to check and follow up interviews with the managing partner. The interviews were published on social media and local printed newspapers, making it easier to understand the birth of the company and the path taken by its founder Amanda Procópio. The research addresses the theme of entrepreneurship, but also the succession process of the family business, with the main challenges being the continuity of a successful business. In this sense, the article

\footnotetext{
${ }^{1} G$ raduação em Administração (2004). Especialização em Planejamento Empresarial e Mestrado em Gestão Empresarial pela Universidade Autônoma de Lisboa/Portugal, título reconhecido no Brasil pela Universidade Federal do Ceará. Coordenou durante 6 anos o curso de ensino superior em Administração e os cursos de Pós- Graduação Lato Sensu, Trabalhou em ONGs, atuando como coordenadora de Projeto para captação de recursos financeiros. Tem experiência no processo de autorização, reconhecimento e renovação de reconhecimento de cursos superiores, assim como, credenciamento e recredenciamento da IES. Experiência como docente e tutora de cursos EAD. Ministra as disciplinas: Planejamento Estratégico. Gestão Ambiental. Introdução a Economia. Gestão de Pessoas. Gestão do Conhecimento. Jogos Empresariais, Metodologia da Pesquisa Científica, entre outras. Atua como pesquisadora em temas: empreendedorismo e sustentabilidade. Professora do Ensino Superior. Mestrado em Gestão Empresarial pelo Instituto Superior em Gestão - ISG Lisboa/Portugal. E-mail: cleide_ferreiraalves@yahoo.com.br
} 
makes it possible to investigate other topics, which may serve for future research.

\section{INTRODUÇÃO}

Em meados da década de 1990, o movimento do empreendedorismo surgiu no Brasil com a criação de entidades como SEBRAE e a Sociedade Brasileira de Exportação de 'software', se intensificando nos últimos anos, mais precisamente a partir do ano 2000.

Uma das maiores causas do aumento da criação de novas empresas, sejam elas micro ou pequenas empresas, tem sido o alto índice de desemprego que nos últimos anos só tem crescido devido à crise econômica em que se encontra o país.

Com a crise, o empreendedorismo foi estimulado, logo, cada vez mais pessoas abrem novos negócios pela falta de renda. Outro fator que justifica o crescimento do empreendedorismo no Brasil são os dados referentes aos principais sonhos dos brasileiros, criar e operar seu próprio negócio, tendo liberdade para tomar decisões sem prestar conta e nem depender da aprovação de terceiros.

Em 2019, a taxa total de empreendedorismo para o Brasil (TTE) foi de 38,7\%, significa que em torno de 53,5 milhões de brasileiros com idade entre 18 e 64 anos estavam envolvidos na criação ou manutenção de algum negócio, na condição de empreendedor em estágio inicial ou estabelecido. (GEM - Global Entrepreneurship Monitor realizada em 2019).

Quando se trata do crescimento do empreendedorismo feminino, considera-se a equiparação de direitos entre os sexos, na medida que, ao galgarem posições cada vez mais relevantes no mundo dos negócios, as mulheres passam a reivindicar seu reconhecimento como personagens participantes do crescimento econômico.

Segundo a pesquisa GEM - Global Entrepreneurship Monitor realizada em 2019, as mulheres brasileiras conseguem criar novos negócios na mesma proporção que os homens. A pesquisa destaca que homens e mulheres são igualmente ativos em estágio inicial do negócio, ambos entre 18 e 34 anos.

Quanto ao segmento de negócio, a mulher geralmente vai para uma área que ela identifica-se, como é o caso do mercado da estética. O Brasil é o terceiro mercado 
global de beleza, ficando atrás apenas da China e dos Estados Unidos (Revista Pequenas Empresas \& Grandes Negócios, 2019).

O crescimento do mercado da beleza foi impulsionado pelos novos empreendedores, que identificaram neste mercado, uma oportunidade de negócio lucrativo.

A pirâmide de Maslow, classifica a necessidade da beleza e do bem-estar no nível da estima, porém hoje, essa classificação pode ser considerada como uma necessidade básica, porque estar belo é sobreviver às exigências da sociedade.

Neste sentido, justifica-se a pesquisa, pois se tratando do mercado da beleza, é um segmento que impulsiona a economia em nosso país, criando oportunidades de geração de empregos e renda. Assim, a presente pesquisa buscou verificar, através de um estudo de caso, a trajetória de sucesso da empresa Amanda Beauty Center, localizada na cidade Manaus, Amazonas.

\section{EMPREENDEDORISMO}

O empreendedorismo é visto em diversos conceitos diferentes, tendo sua origem na Idade Média e sendo conceituado por diversos autores em diversas épocas. Segundo Chiavenato (2008, p. 03), tem por origem do verbo francês entreprener, que significa "aquele que assume riscos e começa algo novo". O empreendedorismo é um processo que envolve a criação de algo inovador e que obtenha valor, pois empreender é uma decisão difícil, principalmente no Brasil, com carga tributária alta e excesso de burocracia.

Para Hisrich; Drucker (2004) o empreendedorismo é um processo de criar algo diferente e com valor, dedicando o tempo e o esforço necessário, assumindo os riscos financeiros, psicológicos e sociais. Ambos os autores citam o empreendedorismo como um "processo" e, de fato é, pois precisa de iniciativa e está relacionado a implementação e inovação constante.

Deste modo, o empreendedorismo é um processo dinâmico pelo qual indivíduos identificam ideias e oportunidades econômicas e atuam desenvolvendo-as, 
transformando-as em empreendimentos e, portanto, reunindo capital, trabalho e outros recursos para produção de bens e serviços.

Para Neto; Froes (2002) existem quatro correntes de estudos e desenvolvimento do empreendedorismo, conforme quadro abaixo:

Quadro I: As correntes de pensamento sobre o empreendedorismo

\begin{tabular}{|c|c|c|c|c|}
\hline Correntes & $\begin{array}{l}\text { Empreendedorismo } \\
\text { Como fomento } \\
\text { tecnológico }\end{array}$ & $\begin{array}{l}\text { Empreendedorismo } \\
\text { como gestão }\end{array}$ & $\begin{array}{l}\text { Empreendedorismo } \\
\text { como estratégia de } \\
\text { desenvolvimento }\end{array}$ & $\begin{array}{l}\text { Empreendedorismo } \\
\text { como estratégia de } \\
\text { desenvolvimento } \\
\text { das PME's }\end{array}$ \\
\hline Objetivo & $\begin{array}{l}\text { Criar, desenvolver e } \\
\text { gerenciar empresas } \\
\text { emergentes }\end{array}$ & $\begin{array}{l}\text { Difundir a pratica } \\
\text { da } \\
\text { empreendedo } \\
\text { empra }\end{array}$ & $\begin{array}{l}\text { Difundir politicas } \\
\text { de DLIS com base } \\
\text { no fomento ao } \\
\text { empreendedorismo } \\
\text { local }\end{array}$ & $\begin{array}{l}\text { Garantir o } \\
\text { desenvolvimento } \\
\text { das micro e PME's }\end{array}$ \\
\hline Foco & $\begin{array}{l}\text { Empresas } \\
\text { emergenciais }\end{array}$ & Melhoria da gestão & $\begin{array}{l}\text { Maior } \\
\text { desenvolvimento } \\
\text { econômico e social } \\
\text { em nível local }\end{array}$ & $\begin{array}{l}\text { Auto } \\
\text { sustentabilidade das } \\
\text { micros e PME's }\end{array}$ \\
\hline Locus & Incubadoras & $\begin{array}{l}\text { Universidades, } \\
\text { escolas de negócios, } \\
\text { programas MBA }\end{array}$ & $\begin{array}{l}\text { Agencias e fóruns } \\
\text { locais de DLIS }\end{array}$ & $\begin{array}{l}\text { Sistema } \\
{ }_{5} \mathrm{~S} / \mathrm{SEBRAE}\end{array}$ \\
\hline
\end{tabular}

Fonte: Adaptado de NETO; FROES (2002, p.7)

Segundo os autores, elas não são excludentes, pois tem seguidores de uma ou mais dessas correntes. Na pesquisa GEM (2019) - Global Entrepreneurship Monitor, revela que, para os brasileiros em geral, independentemente de serem ou não empreendedores, o sonho de possuir um negócio próprio é maior do que o sonho de desenvolver uma carreira profissional em uma empresa pública ou privada, indicando que a sociedade brasileira enxerga na alternativa do empreendedorismo a melhor e mais compensadora forma de atuação profissional.

No Brasil o SEBRAE - Serviço Brasileiro de Apoio às Micro e Pequenas Empresas, ainda é o caminho para quem busca empreender. Além de incentivar a 
criação de novos empreendimentos, promove cursos, treinamentos, palestras e consultorias voltados ao empreendedorismo.

\section{PERFIL EMPREENDEDOR}

Muitas vezes usamos os termos empreendedor e empresário como sinônimos, mas, na verdade, eles não têm o mesmo sentido. Para Maximiano (2012, p. 4) "empresário representa o lado formal, que estabelece um negócio e o conduz no dia a dia”. Já o empreendedor é criativo e inovador.

Maximiano (2012) destaca quatro traços do perfil empreendedor:

$\checkmark$ Criatividade e capacidade de implementação;

$\checkmark$ Disposição para assumir riscos;

$\checkmark$ Perseverança e otimismo;

$\checkmark$ Senso de independência.

Para o autor o empreendedor é aquela pessoa que está sempre fazendo planos e idealizando coisas novas. $\mathrm{O}$ fato de iniciar um negócio é uma experiência que sempre terá sabor de aventura. $\mathrm{O}$ empreendedor tem um compromisso com a prosperidade do seu negócio e, acima de tudo, ele tem autonomia, trabalhando para si mesmo, não para outros.

\section{I.I Vantagens e desvantagens de ser um empreendedor}

São tentadoras as vantagens para quem se propõe a criar e a operar um negócio próprio. Entretanto, existe o outro lado do negócio, que muitas das vezes é estressante e requer muita responsabilidade.

Maximiano (2012) cita que as principais vantagens e desvantagens de se tornar um empreendedor.

Vantagens:
$\checkmark$ Autonomia.
$\checkmark$ Desafio.
$\checkmark$ Controle financeiro. 
Desvantagens:

$\checkmark$ Sacrifício pessoal.

$\checkmark$ Sobrecarga de responsabilidade.

$\checkmark$ Pequena margem de erro.

A autonomia significa a liberdade para tomar decisões sem prestar conta nem depender da aprovação de terceiros. Já o desafio para o empreendedor, é uma fonte de entusiasmo e a recompensa por seu trabalho é o resultado de seu negócio. Por outro lado, existem às desvantagens, que segundo o autor, o empreendedor precisa se dedicar integralmente ao seu negócio, significa que ele é quem vai delegar, pois, não há ninguém acima dele. Desse modo, as estratégias são definidas de forma profissional e nada pode dar errado.

\section{EMPRESAS FAMILIAR}

Para compreender o funcionamento de uma Empresa Familiar, é necessário verificar alguns conceitos abordados pelos autores.

Segundo Oliveira (2006, p. 03) “A empresa familiar caracteriza-se pela sucessão do poder decisório de maneira hereditária a partir de uma ou mais famílias”. São os membros da própria família que acabam assumindo o comando da empresa, legado que, geralmente, é passado de pai para filho.

Já Ricca (2004, p.II) afirma que "a maioria das empresas se inicia com as ideias, o empenho e o investimento de indivíduos empreendedores e seus parentes”. Para o autor, a empresa nasce de uma visão empreendedora e, essa, pode ser passada muito cedo para os demais membros da família. Filhos de casais que cresceram acompanhando seus pais na empresa, acabam aperfeiçoando-se com o negócio.

Uma empresa familiar pode ser de propriedade de uma, ou, mais famílias. Em geral, sua gestão administrativa fica a cargo dessa família, dois, ou, mais membros dela integram a diretoria e participam da força de trabalho.

Dados do SEBRAE - Serviço Brasileiro de Apoio às Micro e Pequenas Empresas, apontam que as empresas familiares se diferenciam das demais, especialmente nestes aspectos:

$\checkmark$ Decisões emocionais. 
Transferência de crises.

Dificuldades para concretizar a descentralização.

$\checkmark$ Lealdade e dedicação como critérios de recursos humanos.

$\checkmark$ Confiança mútua.

$\checkmark$ Dificuldade em separar a família da empresa.

$\checkmark$ Existência de conflitos.

Busca por sucessor com perfil igual ao perfil do sucedido.

As empresas familiares assim como as tradicionais visam o lucro, porém na empresa familiar, o objetivo é melhorar a condição socioeconômica da família. Como envolve membros da família, herdeiros, descendentes e seus cônjuges, a divisão dos lucros acaba se tornando um problema que pode levar a dissolução do negócio, mesmo que haja sentimento do legado deixado pelo seu fundador.

\section{I.I Sucessão na Empresa Familiar: definições}

${ }^{2} \mathrm{O}$ Dicionário apresenta algumas definições de sucessão, como segue:

$\checkmark$ Ação de quem assume o lugar ou trabalho de outra pessoa; substituição.

$\checkmark$ Transmissão dos direitos e bens de quem faleceu; herança.

$\checkmark$ Conjunto dos herdeiros ou de quem descende de alguém falecido; prole ou descendência.

Para Theodoro (2014), o termo sucessão, de forma geral, caracteriza a transferência de direitos e obrigações de uma pessoa para outra.

Segundo Oliveira (2010, p. II), "o processo sucessório representa um dos momentos mais importantes para que se otimize a continuidade da empresa familiar".

Leone (2010) aponta que sucessão familiar, bem como a transferência das responsabilidades e das obrigações de uma empresa para os futuros herdeiros, costuma encontrar uma certa resistência por parte dos fundadores com receio de transferir a responsabilidade para o sucessor. Várias dificuldades são encontradas durante a transição, por isso a importância de ter uma boa preparação para chefiar a sucessão.

\footnotetext{
${ }^{2}$ Dicionário Online de Português, definições e significados de mais de 400 mil palavras. Todas as palavras de A a Z.
} 
Essa preparação citada por Leone (2010), significa que não basta somente herdar a empresa, é necessário feeling para os negócios e muita dedicação, que envolve estudo sobre o mercado, inteligência emocional, e por fim, jogo de cintura para lidar com os problemas familiares.

\section{METODOLOGIA}

A pesquisa caracteriza-se como um estudo de caso, explicativo descritivo, com abordagem qualitativa na coleta dos dados. De acordo com Gil (2009) ressalta que o conceito de caso ampliou-se, a ponto de poder ser entendido como uma família ou qualquer outro grupo social, um pequeno grupo, uma organização, conjunto de relações, um papel social, um processo social, uma comunidade, uma nação ou mesmo toda uma cultura.

Para Gil (2009) o método de estudo de caso consiste num estudo profundo e exaustivo de um, ou poucos objetos, de maneira que permita seu amplo e detalhado conhecimento.

Segundo Yin (2005), o uso do estudo de caso é adequado quando se pretende investigar o como e o porquê de um conjunto de eventos contemporâneos. $\mathrm{O}$ autor assevera que o estudo de caso é uma investigação empírica que permite o estudo de um fenômeno contemporâneo dentro de seu contexto da vida real, especialmente quando os limites entre o fenômeno e o contexto não estão claramente definidos.

O artigo também contou com a pesquisa bibliográfica, pois Fachin (2003), afirma que essa constitui o ato de ler, selecionar, fichar, organizar e arquivar tópicos de interesse para a pesquisa. Para dar subsídio a pesquisa, utilizou-se referencias em livros, artigos e sites.

O caso estudado refere-se a uma empresa familiar do ramo: salão de beleza, localizada em Manaus, Amazonas. Nas etapas de delineamento da pesquisa, buscouse definir o tema e depois delimitá-lo. Após a delimitação, foram verificadas e analisadas as entrevistas disponibilizadas nas mídias sócias. Para validar às informações, foram feitas comparações dos dados encontrados na página da empresa, onde relata a biografia de sua fundadora. 
Quanto a autorização e validação das informações, citadas no artigo, essas foram cedidas pelo herdeiro da empresa.

\section{ESTUDO DE CASO: Amanda Beauty Center}

A AMANDA BEAUTY CENTER EIRELI é uma Empresa Individual De Responsabilidade Limitada, fundada em 30/o6/2008. Sua atividade principal é Cabeleireiros. Nome Fantasia: Amanda Beauty Center. Localizada: Avenida Djalma Batista, I66r, loja 209 Millennium Center.

- Missão: Oferecer serviços e produtos de qualidade, contribuindo para que as pessoas se sintam mais bonitas, aumentando sua autoestima e elevando bem estar.

$>$ Visão: ser o salão de beleza da maior confiança do mercado e com isso atingir a marca de io salões de beleza até 2023 .

$>$ Valores: Amor, qualidade e comprometimento.

\section{I HISTÓRIA}

A história do Amanda Beauty Center iniciou-se há mais de 40 anos em Manaus, quando a proprietária, Amanda Procópio da Silva, após o falecimento de sua mãe teve que iniciar seu próprio negócio para ajudar no sustento da família. Amanda era segunda filha mais velha de sete irmãos.

Em 1965, Amanda Procópio teve seu primeiro contato com a profissão de cabeleira no salão da Dona Maria. 1968. Aos 16 anos, Amanda e sua irmã, Regina, abrem um salão na Rua Ajuricaba no bairro Cachoeirinha. Na década de 7o, especificamente, 1972, ocorre a mudança da sede do primeiro salão para a Rua Castelo Branco, no mesmo bairro. Em 1978, às irmãs, Amanda, Cecy e Regina abrem a empresa que até hoje é a matriz dos salões existentes. No ano de 2005, ocorre a mudança do salão para o Manaus Casa Shopping, na Av. Djalma Batista, um local mais centralizado, onde Amanda poderia alcançar novos clientes. 
$\mathrm{O}$ ano de 2005, foi marcado pelo falecimento da Amanda Procópio, em decorrência de um aneurisma cerebral. No mesmo ano, o Amanda Beauty Center reabre, agora sendo comandado por seu filho Alberto Pontes.

\subsection{LEGADO}

Em 2005, com o falecimento de sua mentora, o Amanda Beauty Center passa a ser dirigida pelo seu único filho e administrador de empresas Luiz Alberto Pontes, com técnica, conhecimento e paixão transformou em pouco tempo, o sonho de sua mãe em uma rede de centros de beleza cujo aperfeiçoamento profissional, ética, excelência e, acima de tudo, o amor, são seus maiores valores.

Ainda criança, Luiz Alberto teve incentivo da mãe para ajudar no salão, pois segundo ele, "sua mãe deixava claro como era importante ele saber de onde vinha o dinheiro". Já com perfil empreendedor, Luiz Alberto, Beto como é chamado, revolucionou o salão Amanda Beauty, tanto na estrutura física, como nos processos.

No ano 2008, Beto inaugura a segunda unidade do salão Amanda no Millennium Shopping. Em 2009 a abertura da terceira unidade do salão Amanda no Manauara Shopping. Em 2013, mudança do Amanda Beauty Center MS Casa, para o Shopping Ponta Negra.

Já em 2016, a Sala Man transforma-se em Barbearia Procópio e, no ano seguinte, 2017, inauguração da Academia Amanda. Um espaço destinado a oferecer uma programação mensal de cursos, com as mais variadas abordagens, da área capilar à estética, disponibilizando opções de cursos para quem deseja adquirir habilidades e desenvolver técnicas especializadas.

Hoje o salão de luxo Amanda Beauty Center, oferece serviços variados como: estética, manicure, podologia, salão masculino exclusivo, fisioterapeuta estética com diversos tratamentos corporais, faciais e salão feminino que contém os melhores produtos nacionais e internacionais.

Além dos serviços, O Grupo revende grandes marcas como Kérastase, Redken, Lóreal Prosissionel, Wella, entre outros. 
A qualificação profissional é uma das características mais fortes da Amanda Beauty Center. Adotada em toda rede uma política de incentivo educacional, permitindo aos seus colaboradores, constantes atualizações das técnicas profissionais das mais novas tendências nacionais e internacionais do mundo da beleza e do bemestar.

A maioria dos profissionais Amanda Beauty Center possuem cursos de qualificação nos principais centros técnicos.

\subsection{FRANQUIA}

Em 2015, na tentativa de expandir o negócio para um novo nicho de mercado, atendendo a classe B e C, cujas necessidades particulares são pouco exploradas ou inexistentes, $\mathrm{O}$ Grupo Amanda Beauty Center abri sua franquia titulada como “Espaço Amanda”. Segundo Luiz Alberto: “O Espaço Amanda, surgiu para atender clientes que valorizam a praticidade e a qualidade sem pagar a mais por isso". O ambiente com decoração "vintage" e profissionais selecionados e treinados no padrão Amanda, diz Luiz Alberto.

As franquias estão localizadas em 5 endereços: Amazonas Shopping, Sumaúma Park Shopping, e nos bairros Adrianópolis, D Pedro e Pıo. Há uma perspectiva de expansão para bairros das principais zonas de Manaus. Os serviços são personalizados e padronizados com intuito de atender os clientes com a mesma qualidade de toda rede Amanda Beauty Center.

\subsection{MARKETING DIGITAL}

Para divulgar o salão, O Grupo Amanda Beauty Center, disponibiliza no seu site todos os serviços oferecidos, além de uma pesquisa de satisfação. Conta, também, com os digitais influencers (influenciadores digitais), pessoas ligadas ao mundo da moda, estética e fitness. Os influenciadores internos, são os colaboradores que divulgam suas técnicas nas redes sociais. "Isso traz ao salão uma maior propagação, em termo de aproximação do público com a marca”, diz Luiz Alberto.

As mídias sociais são impulsionadoras e dão visibilidade ao negócio. Só no Instagram Amanda Beauty Center, têm 62,7 mil seguidores no Facebook 20.120 
seguidores e no Canal do YouTube 823 inscritos. Isso representa o alcance das mídias sociais.

Como aliado para conhecer o perfil do público, a empresa utiliza a avaliação do Facebook e do Google Essa avaliação contém, obrigatoriamente, uma nota que varia de I estrela a 5 estrelas. É possível também avaliar a página com um comentário. "Essa funcionalidade permite que as pessoas que ainda não conhecem o salão visualize os serviços oferecidos", diz Luiz Alberto.

Em 2020, ocorreu o lançamento do e-commerce de produtos e serviços do Amanda Beauty e do aplicativo de agendamento do salão.

\subsection{DESAFIOS}

A expansão das franquias trouxe para o Grupo Amanda Beauty Center alguns desafios, como, por exemplo, entender as dificuldades que cada franquiado terá dentro do negócio, obviamente o lucro é fundamental, mas existem os processos que devem, rigorosamente, serem cumpridos pelo franquiado. Esses processos vão desde do gerenciamento da franquia, até o profissional que será contratado, se os produtos são de qualidade, se as técnicas estão sendo bem aplicadas.

Nesse sentido, O Grupo chegou à conclusão que deveria congelar a expansão de novos franquiados, até que se tenha certeza que os processos estão sendo cumprido na integrar.

\section{CONCLUSÃO}

A pesquisa buscou apresentar, através de fundamentação teórica, conceitos sobre o empreendedorismo, empreendedor e empresas familiares. Essas informações foram importantes para comparar com o caso pesquisado.

Fazendo um paralelo entre as definições dos autores, quanto ao empreendedorismo, empreendedor e a empresa familiar, verifica-se que o sucesso da empresa Amanda Beauty Center, deve-se a visão empreendedora do herdeiro que assumiu o negócio da família.

A empresa passou por um processo de inovação, tanto na estrutura, como na forma de conduzir o negócio, definindo pontos estratégicos de instalação dos salões 
que pudessem atender a um público específico. Buscou-se parceria com as grandes marcas de cosméticos, com o intuito de oferecer mais esse serviço para os clientes.

Quanto aos colaboradores, a empresa se preocupa com qualificação profissional, oportunizando a realização de cursos no país e no exterior. Já o marketing da empresa é feito através das mídias sociais, mas também, com a ajuda dos próprios colaboradores que divulgam os serviços realizados.

Uma forma de obteve feedeback dos serviços prestados, consistir em uma avaliação quantitativa i a 5 estrelas. Esse tipo de avaliação acaba se tornando um mecanismo para verificar os pontos fortes, mas também, para verificar às fragilidades e corrigi-las, melhorando os processos internos.

Para venda de seus produtos e serviços, a empresa apostou no comércio eletrônico (e-commerce), assim, os clientes podem fazer suas compras de qualquer dispositivo eletrônico na comodidade da sua casa.

No futuro, a empresa pretende continuar com as franquias, mas para essa operação alcançar o resultado satisfatório, será necessário que os franquiados consigam realizar todas as etapas do processo que são oferecidos pelo franqueador (equipe qualificada, produtos e técnicas aplicadas) é o que relata o CEO da empresa.

Podemos concluir que Amanda Beauty Center, conseguiu consolidar-se como uma empresa de sucesso em seu segmento, graças a determinação, entusiasmo e visão empreendedora de Luiz Alberto Pontes (herdeiro da empresa), obviamente, sem esquecer a trajetória e o legado deixado por sua mãe Amanda Procópio.

\section{REFERÊNCIAS}

CHIAVENATO, I. Empreendedorismo: dando asa ao espírito empreendedor. 2. ed. São Paulo: Saraiva, 2008.

FACHIN, Odília. Fundamentos de metodologia. 4. ed. São Paulo: Saraiva, 2003. GIL, Carlos. Como elaborar projetos de pesquisa. 4. ed. São Paulo: Atlas, 2009. HISRICH, R. D., Peter, M. P. Empreendedorismo. Porto Alegre: Bookman, 2004. LEONE, N. M. C. P. G. (Org.) e outros. Empresa familiar: desvendando competências, racionalidades e afetos. São Paulo: Atlas, 2010. 
MAXIMIANO, Antônio. Empreendedorismo. São Paulo: Pearson, 2012.

NETO, FRANCISCO; FROES, CÉSAR. Empreendedorismo Social: a transição para sociedade sustentável. Rio de Janeiro: Qualitymark, 2002.

OLIVEIRA, Djalma. Empresa Familiar. 2. ed. São Paulo: Atlas, 2006.

Empresa Familiar: como fortalecer o empreendimento e otimizar o processo sucessório. 3 ed. São Paulo: Atlas, 2010.

RICCA, Domingos. Sucessão na Empresa Familiar: Conflitos e Soluções. São Paulo: Cla editora, 2004.

YIN, R. K. Estudo de caso: planejamento e métodos. 3. ed. Porto Alegre: Bookman, 2005 .

Theodoro, E. T. (2014). Categorias e conceitos pertinentes ao direito sucessório, procedimentos e formas de atuação. (2014). Recuperado de https://jus.com.br/artigos/34I 03/direito-sucessório-linhas-gerais. Acesso em I2 abril 2021.

http://www.bibliotecas.sebrae.com.br/chronus/ARQUIVOS_CHRONUS/bds/bd s.nsf/941a5Iddo4d5e55430088dbira262802/\$File/7592.pdf. Acesso em i2 abril. 2021. http://revistapegn.globo.com/Administracao-de-empresas/noticia/2016/12/3mudancas-que-vao-afetar-o-mercado-de-beleza-brasileiro-em-2017.html. Acesso em I4 abril. 2021.

https://www.youtube.com/watch?v=Mc_vmOzKlIA\&t=28Is. Acesso em I4 abril.2021.

https://www.sebrae.com.br/Sebrae/Portal\%2oSebrae/UFs/TO/Anexos/Sucess\%C 3\%A30\%20Empresarial.pdf. Acesso em i4 abril. 2021.

https://pacotes.amandabeautycenter.com.br/Folder.pdf. Acesso em 19 abril. 2021. 